\title{
Aa. Vv., Sur les pas d'Henry Bauchau, in «Revue Générale», n. 11
}

\section{Michele Mastroianni}

\section{(2) OpenEdition}

\section{Journals}

\section{Edizione digitale}

URL: http://journals.openedition.org/studifrancesi/8081

DOI: 10.4000/studifrancesi.8081

ISSN: 2421-5856

\section{Editore}

Rosenberg \& Sellier

\section{Edizione cartacea}

Data di pubblicazione: 1 juillet 2009

Paginazione: 443

ISSN: 0039-2944

\section{Notizia bibliografica digitale}

Michele Mastroianni, «Aa. Vv., Sur les pas d'Henry Bauchau, in «Revue Générale», n. 11», Studi Francesi [Online], 158 (LIII | II) | 2009, online dal 30 novembre 2015, consultato il 08 janvier 2021. URL: http:// journals.openedition.org/studifrancesi/8081 ; DOI: https://doi.org/10.4000/studifrancesi.8081

Questo documento è stato generato automaticamente il 8 janvier 2021.

\section{(c) (i) $\ominus$}

Studi Francesi è distribuita con Licenza Creative Commons Attribuzione - Non commerciale - Non opere derivate 4.0 Internazionale. 


\title{
Aa. Vv., Sur les pas d'Henry Bauchau, in «Revue Générale», n. 11
}

\author{
Michele Mastroianni
}

\section{NOTIZIA}

Sur les pas d'Henry Bauchau, in «Revue Générale», n. 11, novembre 2007, pp. 9-59.

1 Ancora fra gli studi che sono usciti nel tournant 2007-08, segnaliamo questo numero della «Revue Générale», in buona parte dedicato all'autore belga, secondo una prospettiva che concilia il côté storico da un lato e il côté letterario dall'altro. Apre proprio Henry BAUCHAU, Mary, gare du Nord (inédit), con alcune pagine (9-15) estratte dal romanzo Le Boulevard périphérique, recentemente pubblicato da Actes Sud (2008), ove rivissuto e trasposto in finzione letteraria è il passato dell'autore, ricostruito con un'immissione cronologica e contrario, che tiene conto del periodo della guerra, in particolare gli anni che vanno dal 1940 al 1945. Myriam WATTHEE-DELMOTTE, Henry Bauchau et Louvain: longue histoire et nouvel avenir (pp. 17-24), insiste sul ruolo importantissimo di questa città nel vissuto di Bauchau, visto che la sua vita, proprio a Louvain, fu segnata da una primissima frattura esistenziale, causata dalla separazione dalla madre (siamo nei primi mesi dalla nascita), e sconvolta in seguito, ancora nella complessità di un inconscio presente e in fieri, dalla distruzione dei beni di famiglia (siamo nel 1914). Sarà poi l'incendio di una biblioteca plurisecolare di Louvain a segnare ancora una volta la sua vita. Lovanio dunque, ville di dolore, ma al tempo stesso città di affermazione e riconoscimento pubblico, luogo di studio giovanile ove Bauchau, fra il 1935 e il 1939, si specializzò in diritto; e ancora Lovanio, luogo e centro di ricerca intorno all'opera bauchauliana, ma anche sede di una prestigiosa Università che accoglie Bauchau per una importante serie di conferenze, pubblicate ne L'Écriture et la Circonstance (Louvain-la-Neuve, Publications de la Faculté de Philosophie et Lettres de l'U.C.L., «Chaire de poétique de l'Université Catholique de Louvain», 1988), a testimonianza illustre di un discorso letterario moderno e in cammino su cui la critica attuale sempre più si concentra. Questi dunque i punti di interesse indagati da 
Watthee-Delmotte. Geneviève DUCHENNE e Vincent DUJARDIN, Henry Bauchau: d'un aprèsguerre à l'autre (pp. 25-40) concentrano la loro attenzione su ciò che Bauchau è stato prima del riconoscimento letterario, prima dell'indiscussa abilità poetica. Tentando quindi di apportare alle indagini letterarie su Bauchau nuovo materiale e nuovi elementi di interesse, essi indagano dati personali e pubblici, nella prospettiva di colmare le lacune che sotto il profilo più propriamente storico ancora persistono intorno a questo autore. Tra gli elementi che emergono come determinanti, seppure in chiave negativa, l'amicizia con il pubblicista Raymond De Becker e la militanza di Bauchau, dal luglio 1940 al giugno 1943, nel Service des Volontaires du Travail, esperienze totalizzanti e tragiche, sia per l'uomo, sia per lo scrittore che sarà in seguito. Isabelle VANQUAETHEM, L'Itinéraire spirituel des personnages dans l'œuvre romanesque d'Henry Bauchau (pp. 41-46) cerca di dare ragione delle intime evoluzioni di alcuni dei personaggi bauchauliani (Pierre, Edipe, Antigone, Orion, Véronique), ripercorrendo parte della produzione letteraria romanzesca (dal 1960 al 2004) dell'autore. Werner LAMBERSY, Propos d'un poète sur un autre poète (pp. 47-53), rivive la sua amicizia con Henry Bauchau e la inquadra all'interno di un contesto in cui la poesia è elemento fondante e saldante; Jean-Pierre JossuA, Dans l'atelier spirituel (pp. 55-59), ricorda le fasi spirituali lungo cui passa l'autore (adesione alla confessione cattolica, rifiuto del cattolicesimo, predisposizione per una spiritualità lontana dall'istituzione in quanto tale), isola alcune pagine o passi del ciclo edipico bauchauliano o ancora, nel caso, alcuni momenti tratti dai journaux, nel tentativo di offrire un panorama di questa laboriosissima spiritualità. 